\title{
Membudayakan Keterampilan Menulis pada Mading Kelas untuk Melatih Kreativitas Siswa
}

\author{
Arnelia Dwi Yasa*1, Denna Delawanti Chrisyarani2 \\ 1,2Universitas Kanjuruhan Malang \\ 1,2PGSD, Fakultas Ilmu Pendidikan, Universitas Kanjuruhan Malang \\ *e-mail: arnelia@unikama.ac.id ${ }^{1}$, dennadelawanti@unikama.ac.id ${ }^{2}$
}

\begin{abstract}
Writing is an inseparable activity from everyday human life. Writing skills can be fostered from diligent reading. One of the reading media as well as the media for pouring student work is mading. Mading is a vehicle for applying students' abilities, especially in the field of writing. MI Manbaul Ulum Karangduren is a school located in Malang Regency. The school does not yet have a class bulletin board containing student work. Thus, the opportunity for students to develop their creativity in writing is hampered. Efforts are needed to improve writing skills for students to build a reading culture. One way is to publish bulletin as a teaching aid and coaching. Through bulletin board, it is hoped that students can have creativity in writing. The results of community service activities show that students' writing skills have improved. The average value of $N$-Gain Creativity Test scores 0.73 in the high category. This shows the level of effectiveness of the treatment has a high effect on the post test.
\end{abstract}

Keywords: writing skills, class wallading, creativity

\begin{abstract}
Abstrak
Menulis merupakan kegiatan yang tidak terpisahkan dari kehidupan manusia sehari-hari. Kemampuan menulis dapat dipupuk dari rajin membaca. Salah satu media bacaan sekaligus media untuk menuangkan karya-karya siswa adalah mading. Mading merupakan wahana untuk menerapkan kemampuan siswa terutama dalam bidang tulis-menulis. MI Manbaul Ulum Karangduren adalah Sekolah yang terletak di Kabupaten Malang. Sekolah belum memiliki mading kelas yang memuat hasil karya tulisan siswa. Sehingga, kesempatan siswa untuk mengembangkan kreativitasnya dalam menulis terhambat. Perlu upaya untuk meningkatkan kemampuan menulis bagi siswa untuk membangun budaya baca. Salah satu cara adalah dengan menerbitkan mading sebagai alat bantu pengajaran dan pembinaan. Melaui mading, diharapkan dapat membuat siswa memiliki kreativitas dalam menulis. Hasil dari kegiatan pengabdian menunjukkan bahwa keterampilan menulis siswa mengalami peningkatan. Rata-rata nilai N-Gain Skor test Kreativitas 0,73 berkategori tinggi. Hal ini menunjukkan tingkat efektivitas dari perlakuan berpengaruh tinggi terhadap post test.
\end{abstract}

Kata kunci: keterampilan menulis, mading kelas, kreativitas

\section{PENDAHULUAN}

Menulis merupakan kegiatan yang hampir tidak terpisahkan dari kehidupan manusia sehari-hari. Seseorang yang ingin memiliki keterampilan mengarang harus sering berlatih (Yunus, 2017). Kemampuan menulis dapat dikembangkan dengan kegiatan membaca. Melalui kegiatan menulis seseorang dapat menuangkan pikiran, ide, dalam bentuk tulisan (Ahsin, 2016). Mading adalah salah satu media bacaan sekaligus media untuk menuangkan karya-karya siswa. Mading merupakan satu jenis media komunikasi tulis yang paling sederhana. Majalah dinding merupakan tempat yang dapat digunakan oleh siswa untuk melatih kemampuan dalam bidang tulis-menulis. Tulisan yang ada di dalam sebuah majalah dinding, pada umumnya merupakan bahan ajar yang ada dalam muatan pembelajaran bahasa Indonesia.

Pada muatan pembelajaran bahasa Indonesia juga terdapat kompetensi dasar seperti penulisan berita, opini, resensi, cerpen, puisi, tajuk rencana, artikel, dan sebagainya. Mading sekolah merupakan salah satu upaya untuk menanamkan budaya literasi (Hidayatullah, Sulistyawati, \& Jupri, 2019). Manfaat mading di sekolah adalah sebagai media komunikasi, media kreativitas, media untuk meningkatkan keterampilan menulis, media untuk melatih kecerdasan berpikir( dkk Ardianik, 2019). 
Ada tiga faktor pendukung dalam menyelenggarakan majalah dinding, yaitu penulis, ilustrator dan dokumentator( dkk Ardianik, 2019). Ketiga faktor tersebut saling terkait satu dengan yang lain dalam melahirkan majalah dinding yang berkualitas. Penulis sebagai sumber utama lahirnya majalah dinding mempunyai kontribusi terbesar dalam penyelenggaraan majalah dinding, Hal ini mengingat bagian terbesar isi majalah dinding berupa tulisan. Selanjutnya, agar majalah dinding menarik dan tidak kaku perlu diberi ilustrasi berbagai bentuk hiasan atau pemanis.

Melalui penampilan aneka variasi, baik warna maupun bentuk gambar, garis atau yang lain, beragam ilustrasi yang pengaturannya diselang-seling akan membuat majalah dinding mempunyai daya tarik. Di sinilah letak pentingnya seorang ilustrator untuk menjadikan majalah dinding agar terlihat menarik bagi pembacanya. Sedangkan seorang dokumentator mempunyai peranan untuk mendokumentasikan, yaitu menyimpan dan mengamankan semua naskah yang pernah dimuat dalam majalah dinding. Naskah-naskah tersebut diklasifikasikan berdasarkan penggolongan naskah, misalnya opini, cerpen, puisi.

Bahasa yang digunakan dalam majalah dinding memiliki ciri-ciri khusus, yaitu singkat, padat, jelas dan komunikatif (Aufa, 2018). Singkat berarti menghindari pemilihan bentuk kata yang kurang ringkas. Padat berarti menggunakan jumlah kata yang sedikit tetapi dapat menjangkau makna yang lengkap. Sedangkan jelas, mengandung makna tidak membingungkan, dan komunikatif mengandung unsur yang mudah dipahami.

MI Manbaul Ulum Karangduren adalah Sekolah yang terletak di Kabupaten Malang. Berdasarkan hasil observasi di MI Manbaul Ulum Karangduren, sekolah belum memiliki mading kelas yang memuat hasil karya tulisan siswa. Sehingga, kesempatan siswa untuk mengembangkan kreativitasnya dalam menulis terhambat. Tidak berarti mereka tidak memiliki potensi untuk menulis. Pada dasarnya banyak siswa yang memiliki potensi untuk menulis, hanya saja potensinya belum terasah karena tidak ada media sebagai tempat untuk menyalurkan ide, gagasan dan kreativitasnya.

Dengan kondisi yang demikian perlu ada upaya untuk meningkatkan kemampuan menulis siswa dan sekaligus membangun budaya baca. Salah satu cara adalah dengan menerbitkan mading sebagai alat bantu pengajaran dan pembinaan yang dapat melatih kreativitas siswa. Pengabdian terkait dengan mading pernah dilakukan oleh fitri (2016) bahwa mading dapat digunakan sebagai pemenuhan kebutuhan informasi siswa. Mading dapat dijadikan media komunikasi siswa (Sari \& Swestin, 2015). Melatih keterampilan menulis siswa dapat difasilitasi dengan menggunakan mading (Satria \& Afnita, n.d.). Perbedaan pengabdian ini dengan pengabdian terdahulu yakni melatih keterampilan menulis cerpen siswa kelas III SD dengan menggunakan mading. Mading yang digunakan pada pengabdian ini adalah mading kelas.

Kegiatan pengabdian ini dilakukan karena dilatar belakangi oleh beberapa permasalahan: 1) Kurangnya pengetahuan tentang manfaat mading bagi siswa. 2) Tidak ada mading yang digunakan sebagai tempat mengekspresikan hasil tulisannya. 3) Pengetahuan siswa tentang cara menulis cerpen dalam mading masih kurang. 4) Rendahnya kemampuan menulis siswa sehingga belum bisa mengahasilkan tulisan yang kretif. Tujuan dilakukan pengabdian ini adalah untuk melatih keterampilan menulis cerpen dengan menggunakan mading kelas. Sesuai dengan analisis situasi yang sudah diapaparkan, jenis pengabdian yang akan diberikan pada sekolah mitra difokuskan pada pengembangan kreativitas menulis siswa kelas III SD melalui mading sekolah.

\section{METODE}

Pengabdian masyarakat ini dilakukan pada siswa kelas III MI Manbaul Ulum. Bentuk program pengabdian masyarakat ini yaitu berupa pelatihan menulis cerpen yang akan dimuat pada mading kelas. Metode yang digunakan dalam kegiatan ini adalah metode ceramah dan metode penugasan. Metode ceramah digunakan untuk menjelaskan dan memberi pemahaman tentang cara menulis cerpen pada mading kelas. Ceramah akan diberikan 1 kali selama 3 jam, 
yang diikuti oleh siswa kelas III MI Manbaul Ulum sebanyak 22 siswa. Peserta melakukan kegiatan tanya jawab selama 30 menit.

Pada metode penugasan, siswa dibagi menjadi beberapa kelompok kemudian diminta untuk membuat cerpen. Penugasan dilakukan sekitar 2 jam. Selama siswa mengerjakan tugas yang diberikan dilakukan monitoring. Selanjutnya, tugas masing-masing kelompok dipresentasikan. Cerpen yang terbaik dimuat dimading kelas. Tugas berikutnya yang diberikan kepada siswa adalah meminta siswa untuk membuat desain mading yang menarik sehingga membuat mading mempunyai daya tarik bagi pembaca.

Bentuk evaluasi yang digunakan untuk menilai cerpen siswa adalah instrument kreativitas menulis. Instrumen penilaian kreativitas siswa digunakan untuk mengukur tingkat kreativitas yang diperoleh siswa setelah membuat cerpen. Tingkat kreativitas siswa dilihat dari kemampuan menulis kreatif yang meliputi 4 kriteria yaitu kelancaran, kelenturuan, keaslian (orisinalitas), dan keterperincian (elaborasi) (Putra, Akhdiyat, Setiany, \& Andiarani, 2018). Kemampuan kreativitas siswa pada saat proses pembelajaran dinilai melalui tes menulis kreatif atau membuat cerpen yang meliputi 4 kriteria yaitu kelancaran, kelenturan, keaslian (orisinalitas), dan keterperincian (elaborasi). Setiap kriteria ada 5 komponen sehingga seluruhnya ada 20 butir yang dinilai, setiap butir yang memenuhi syarat diberi skor 1 sehingga skor maksimal yang dapat diperoleh ialah 20 (Munandar, 2012). Kriteria penilaian menulis kreatif yang dilakukan oleh siswa didasarkan pada Tabel 1.

Tabel 1. Kriteria Penilaian Menulis Kreatif

- Kelancaran, didasarkan atas jumlah kata yang digunakan dalam karangan tersebut.

- Kriteria Kelancaran: Menggunakan lebih dari 100 kata

\begin{tabular}{|c|c|c|}
\hline No & Kriteria & Skor \\
\hline $\mathrm{a}$ & Jika kurang dari 60 kata & 1 \\
\hline $\mathrm{b}$ & $60-70$ kata & 2 \\
\hline $\mathrm{C}$ & $70-80$ kata & 3 \\
\hline $\mathrm{d}$ & $80-90$ kata & 4 \\
\hline $\mathrm{e}$ & Lebih dari 90 kata & 5 \\
\hline
\end{tabular}

- Kelenturan (fleksibelitas), kelenturan dalam struktur kalimat dan kelenturan dalam konten atau gagasan.

- Kriteria kelenturan (fleksibelitas):

Struktur kalimat berkesinambungan, konten kalimat sesuai dengan gambar, keragaman dalam menggunakan kalimat (deklaratif, interogatif), kalimatnya panjang lebih dari 6 kata, kaya imajinasi.

\begin{tabular}{clc}
\hline No & \multicolumn{1}{c}{ Kriteria } & Skor \\
\hline A & Jika 1 kriteria terpenuhi & 1 \\
\hline B & Jika 2 kriteria terpenuhi & 2 \\
\hline C & Jika 3 kriteria terpenuhi & 3 \\
\hline D & Jika 4 kriteria terpenuhi & 4 \\
\hline E & Jika semua kriteria terpenuhi & 5 \\
\hline
\end{tabular}

- Keaslian (Orisinalitas), sejauh mana konten atau gaya pemikiran karangan menunjukkan orisinalitas (ketidaklaziman), dibandingkan dengan karangan yang isi dan gaya penulisannya menunjukkan stereotipe.

- Kriteria Keaslian (Orisinalitas)

Ada judul, orisinalitas dalam pemecahan masalah, menggunakan kata atau nama baru yang ditemukan, orisinalitas dalam gaya penulisan, menggunakan kalimat yang mengandung majas. 


\begin{tabular}{|c|c|c|}
\hline No & Kriteria & Skor \\
\hline $\mathrm{A}$ & Jika 1 kriteria terpenuhi & 1 \\
\hline $\mathrm{B}$ & Jika 2 kriteria terpenuhi & 2 \\
\hline $\mathrm{C}$ & Jika 3 kriteria terpenuhi & 3 \\
\hline $\mathrm{D}$ & Jika 4 kriteria terpenuhi & 4 \\
\hline $\mathrm{E}$ & Jika semua kriteria terpenuhi & 5 \\
\hline
\end{tabular}

- Kerincian (elaborasi, kekayaan), kemampuan untuk membubuhi atau menghiasi cerita sehingga tampak lebih kaya.

- Kriteria Kerincian (elaborasi, kekayaan) :

Karangan menarik, karangan kaya dalam ungkapan perasaan, penggunaan EYD tepat, subjek melibatkan dirinya atau pengalaman pribadi, menggunakan kalimat naratif langsung dengan menggunakan tanda kutip.

\begin{tabular}{clc}
\hline No & \multicolumn{1}{c}{ Kriteria } & Skor \\
\hline A & Jika 1 kriteria terpenuhi & 1 \\
\hline B & Jika 2 kriteria terpenuhi & 2 \\
\hline C & Jika 3 kriteria terpenuhi & 3 \\
\hline D & Jika 4 kriteria terpenuhi & 4 \\
\hline E & Jika semua kriteria terpenuhi & 5 \\
\hline
\end{tabular}

Untuk mengetahui pengaruh pembelajaran terhadap Kreativitas siswa, dilakukan analisis deskriptif kualitatif beruapa analisis N-Gain Score Hake (1999) dengan rumus sebagai berikut :

Keterangan :

$$
(g)=\frac{S_{\text {post }}-S_{\text {pre }}}{S_{\text {mak }}-S_{\text {pre }}}
$$

(g) = nilai gain

Spost $=$ nilai post-test

Spre = nilai pre-test

Smax = nilai maksimal

Gain menunjukkan perbedaan kreativitas siswa sebelum dan setelah diberikan perlakuan. Gain skor ternomalisasi menunjukkan tingkat efektivitas perlakuan dari pada perolehan skor atau post test. Nilai (g) yang diperoleh diinterpretasikan dengan klasifikasi pada Tabel 2.

Tabel 2 Interpretasi Nilai Gain yang Dinormalisasi

\begin{tabular}{cc}
\hline Nilai (g) & Interpretasi \\
\hline$(\mathrm{g}) \geq 0,7$ & Tinggi \\
\hline $0,7>(\mathrm{g}) \geq 0,3$ & Sedang \\
\hline$(\mathrm{g})<0,3$ & Rendah \\
\hline
\end{tabular}

(Hake, 1999)

\section{HASIL DAN PEMBAHASAN}

Kegiatan pelatihan dan pendampingan ini dilakukan dengan menggunakan tiga metode yakni: (1) Metode ceramah; (2) Metode Diskusi; (3) Latihan Praktek (drill practice). Tim pengabdi menggunakan metode ceramah dengan bantuan media laptop dan LCD. Kegiatan pengembangan keterampilan menulis dilakukan tim pengabdi dengan memberikan materi tentang keterampilan menulis dengan membuat cerita dengan menggunakan media gambar. Media belajar penting dalam proses pembelajaran dan dapat memotivasi siswa untuk belajar 
(Rismiyenti,2018). Selain itu, kegiatan pengabdian dilanjutkan dengan menjelaskan syarat membuat cerita narasi, menjelaskan cara membuat cerpen.

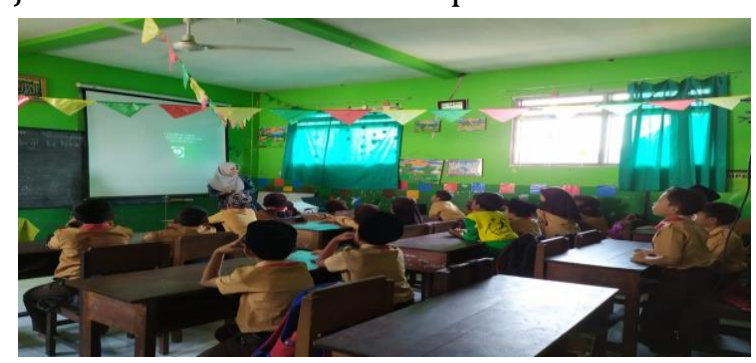

Gambar 1 TIM Memberikan Materi

Tim pengabdi memberikan kesempatan kepada para siswa untuk menyampaikan permasalahan-permasalah yang dihadapi oleh para siswa selama berlatih untuk membuat narasi atau cerpen sederhana. Sehingga, tim pengabdi bisa memberikan masukan kepada siswa atas permasalahan yang dihadapi.

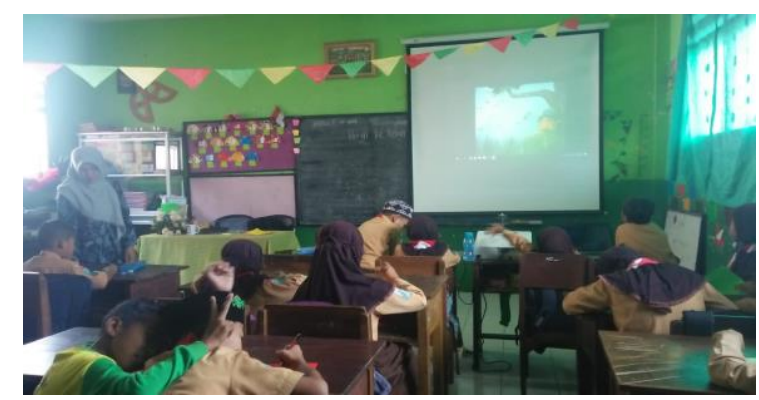

Gambar 2 TIM Mendampingi siswa yang mengalami kesulitan

Setelah kegiatan pendalaman materi dan diskusi selesai, siswa diminta untuk mengaplikasi materi yang diperoleh dengan membuat cerpen sederhana. Setiap siswa berlatih untuk membuat cerpen. Setelah cerpen selesai dibuat, siswa diminta untuk menghias cerpen agar tampak menarik. Kegiatan akhir dari kegiatan pengabdian ini adalah mendisplay cerpen pada madding yang telah disiapkan oleh tim pengabdi.

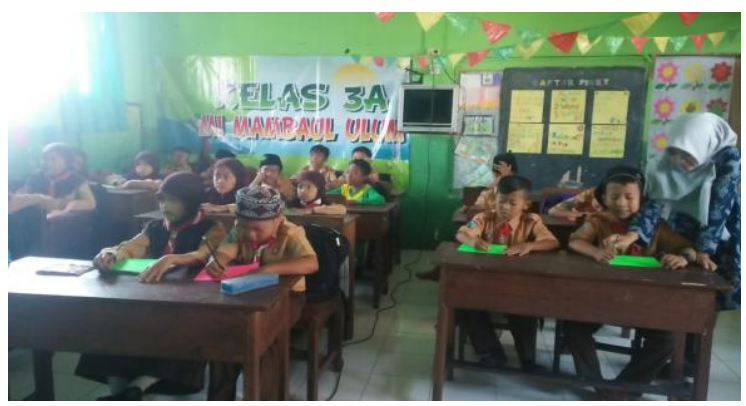

Gambar 3 Praktek Membuat Cerpen

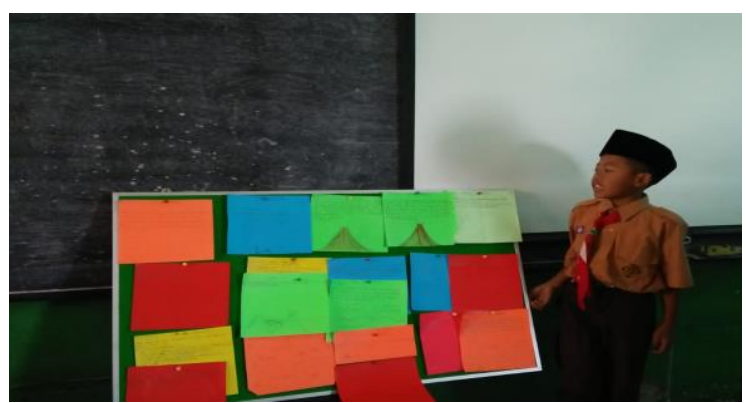

Gambar 4 Display Cerpen 
Bentuk evaluasi yang digunakan untuk mengukur kreativitas menulis siswa berupa keterampilan membuat cerpen. Indikator kreativitas yang dinilai ada empat indikator yakni kelancaran, kelenturan (fleksibelitas), keaslian (orisinalitas), kerincian (elaborasi) (Rhosalia, 2016). Hasil tes kreativitas siswa terdapat pada tabel 3.

Tabel 3 Hasil Tes Kreativitas Siswa

\begin{tabular}{|c|c|c|c|c|}
\hline \multirow[b]{2}{*}{ Siswa } & \multicolumn{4}{|c|}{ Proporsi } \\
\hline & Rata- Rata U1 & Kategori Kreativitas & Rata- Rata U2 & $\begin{array}{c}\text { Kategori } \\
\text { Kreativitas }\end{array}$ \\
\hline 1 & 7 & Tidak Kreatif & 11 & Kreatif \\
\hline 2 & 9 & Tidak Kreatif & 14 & Kreatif \\
\hline 3 & 11 & Kreatif & 16 & Kreatif \\
\hline 4 & 8 & Tidak Kreatif & 12 & Kreatif \\
\hline 5 & 7 & Tidak Kreatif & 14 & Kreatif \\
\hline 6 & 9 & Tidak Kreatif & 15 & Kreatif \\
\hline 7 & 10 & Tidak Kreatif & 16 & Kreatif \\
\hline 8 & 12 & Kreatif & 16 & Kreatif \\
\hline 9 & 6 & Tidak Kreatif & 10 & Tidak Kreatif \\
\hline 10 & 10 & Tidak Kreatif & 15 & Kreatif \\
\hline 11 & 9 & Tidak Kreatif & 14 & Kreatif \\
\hline 12 & 8 & Tidak Kreatif & 13 & Kreatif \\
\hline 13 & 11 & Kreatif & 15 & Kreatif \\
\hline 14 & 6 & Tidak Kreatif & 13 & Kreatif \\
\hline 15 & 9 & Tidak Kreatif & 15 & Kreatif \\
\hline 16 & 10 & Tidak Kreatif & 15 & Kreatif \\
\hline 17 & 11 & Kreatif & 14 & Kreatif \\
\hline 18 & 7 & Tidak Kreatif & 13 & Kreatif \\
\hline 19 & 6 & Tidak Kreatif & 12 & Kreatif \\
\hline 20 & 8 & Tidak Kreatif & 14 & Kreatif \\
\hline 21 & 9 & Tidak Kreatif & 14 & Kreatif \\
\hline 22 & 10 & Tidak Kreatif & 15 & Kreatif \\
\hline
\end{tabular}

Keterangan :

$\mathrm{U} 1=$ Pre test

$\mathrm{U} 2=$ Post test

Skor Kreativitas :

$5-10=$ Tidak Kreatif

$11-16=$ Kreatif

Rentang skor kreativitas siswa didapatkan dari hasil penelitian. Penilaian kreativitas digolongkan menjadi kreatif, tidak kreatif diantara kreatif dan tidak kreatif (Munandar, 1977). Setiap kriteria ada 5 komponen sehingga seluruhnya ada 20 butir yang dinilai, setiap butir yang memenuhi syarat diberi skor 1(Munandar, 2012).

Berdasarkan hasil Tabel 5.5 tersebut hasil pre test memperlihatkan empat siswa berkategori kreatif, 18 siswa berkategori tidak kreatif. Pada post test memperlihatkan satu siswa tidak kreatif dan 21 siswa berkategori kreatif. Untuk mengetahui pengaruh pembelajaran terhadap Kreativitas Siswa, dilakukan analisis deskriptif kualitatif berupa analisis N-Gain Score. Gain menunjukkan perbedaan Kreativitas siswa sebelum dan setelah diberikan perlakuan. Hasil analisis N-Gain Score pada tes Kreativitas Siswa dapat dilihat pada Tabel 5.6.

Tabel 4 Nilai N-Gain Score Pada Tes Kreativitas Siswa

\begin{tabular}{lrrrr}
\hline \multirow{2}{*}{ Siswa } & \multicolumn{2}{c}{ Proporsi } & \multirow{2}{*}{ N-Gain } & \multirow{2}{*}{ Interpretasi } \\
\cline { 2 - 3 } & Rata- Rata U1 & Rata- Rata U2 & \\
\hline
\end{tabular}




\begin{tabular}{ccccc}
\hline \multirow{2}{*}{ Siswa } & \multicolumn{2}{c}{ Proporsi } & \multirow{2}{*}{ N-Gain } & \multirow{2}{*}{ Interpretasi } \\
\cline { 2 - 3 } & Rata- Rata U1 & Rata- Rata U2 & & \\
\hline 1 & 7 & 11 & 0,44 & Sedang \\
\hline 2 & 9 & 14 & 0,71 & Tinggi \\
\hline 3 & 11 & 16 & 1 & Tinggi \\
\hline 4 & 8 & 12 & 0,50 & Sedang \\
\hline 5 & 7 & 14 & 0,78 & Tinggi \\
\hline 6 & 9 & 15 & 0,86 & Tinggi \\
\hline 7 & 10 & 16 & 1 & Tinggi \\
\hline 8 & 12 & 16 & 1 & Tinggi \\
\hline 9 & 6 & 10 & 0,40 & Sedang \\
\hline 10 & 10 & 15 & 0,83 & Tinggi \\
\hline 11 & 9 & 14 & 0,71 & Tinggi \\
\hline 12 & 8 & 13 & 0,63 & Sedang \\
\hline 13 & 11 & 15 & 0,80 & Tinggi \\
\hline 14 & 6 & 13 & 0,70 & Sedang \\
\hline 15 & 9 & 15 & 0,86 & Tinggi \\
\hline 16 & 10 & 15 & 0,71 & Tinggi \\
\hline 17 & 11 & 14 & 0,60 & Sedang \\
\hline 18 & 7 & 13 & 0,67 & Sedang \\
\hline 19 & 6 & 12 & 0,60 & Sedang \\
\hline 20 & 8 & 14 & 0,75 & Tinggi \\
\hline 21 & 9 & 14 & 0,71 & Tinggi \\
\hline 22 & 10 & 15 & 0,83 & Tinggi \\
\hline & Rata-Rata & & 0,73 & Tinggi \\
\hline
\end{tabular}

Berdasarkan tabel tersebut nilai N-Gain Skor test Kreativitas 8 siswa berkategori sedang dengan nilai N-Gain 0,40-0,70. Rata-rata nilai N-Gain Skor test Kreativitas 0,73 berkategori tinggi. Hal ini menunjukkan tingkat efektivitas dari perlakuan berpengaruh tinggi terhadap post test. Mading atau majalah dinding dapat dijadikan sebagai temapat untuk menampung kreativitas dalam menulis dan menyalurkan ide kratif (D. Ardianik, 2019).

\section{KESIMPULAN}

Pengabdian yang dilakukan untuk siswa kelas III Malang telah berjalan dengan baik. Rangkaian kegiatan mulai dari pre test, pemberian materi terkait pengembangan keterampilan menulis (membuat cerita berdasarkan gambar, menjelaskan syarat membuat narasi, menjelaskan cara membuat cerpen) dengan metode ceramah. Pada sesi diskusi, siswa diberikan kesempatan untuk menyampaikan permasalahan-permasalahan yang dihadapi selama membuat cerita. Dilanjutkan dengan latihan praktek, siswa diminta untuk membuat sebuah cerpen. Hasil dari kegiatan pengabdian menunjukkan bahwa keterampilan menulis siswa mengalami peningkatan. Rata-rata nilai N-Gain Skor test Kreativitas 0,73 berkategori tinggi. Hal ini menunjukkan tingkat efektivitas dari perlakuan berpengaruh tinggi terhadap post test. Hasil dari Kegiatan pengabdian ini memberikan banyak manfaat bagi guru, kepala sekolah dan pemateri. Kegiatan pengabdian ini semata-mata dilakukan untuk meningkatkan keterampilan menulis siswa sekolah dasar. Saran untuk pengabdian selanjutnya yakni perlu ditindaklanjuti dan dikembangkan pelatihan yang serupa untuk program lain berdasarkan kebutuhan lapangan.

\section{DAFTAR PUSTAKA}

Ahsin, M. N. (2016). Peningkatan Keterampilan Menulis Karangan Narasi Dengan Menggunakan Media Audiovisual Dan Metode Quantum Learning. Refleksi Edukatika, 6(2), 158-171. 
https://doi.org/10.24176/re.v6i2.607

Ardianik, dkk. (2019). UPAYA MENINGKATKAN KREATIVITAS GURU DAN SISWA SMA ISLAM PARLAUNGAN DALAM MENULIS KARYA TULIS Nilai akreditasi SMA Islam Parlaungan masyarakat ini adalah SMA Islam Parlaungan, 2(1).

Ardianik, D. (2019). Program Pendidikan Bahasa dan Sastra Indonesia , FKIP Universitas Dr . Soetomo, 11.

Aufa, M. (2018). Pku Bagi Mi Muhammadiyah Meduro Melalui Majalah Dinding Mengasah Kreativitas Menulis Dan Gemar Membaca Siswa. Warta LPM, 21(2), 130-135. https://doi.org/10.23917/warta.v21i2.6015

fitri. (2016). DINDING PERPUSTAKAAN DENGAN PEMENUHAN, 3(1), 1-8.

Hake, R. R. (1999). American Educational Research Association's Division D. Measurement and Research Methodology: Analyzing Change/ Gain Scores. USA: Woodland.

Hidayatullah, S., Sulistyawati, S., \& Jupri, A. R. (2019). Pelatihan Mading Sekolah bagi Siswa SMP Muhamamdiyah 19 Sawangan dan SMA Muhammadiyah 07 Sawangan. E-Dimas: Jurnal Pengabdian Kepada Masyarakat, 10(2), 144. https://doi.org/10.26877/e-dimas.v10i2.3300

Munandar, U. (1977). Creativity and Education: A Study of The Relationships Between Measures of Creative Thinking and a Number Of Educational Variabels in Indonesian Primary and Junior Secondary Schools. Jakarta: Dep P \& K.

Munandar, U. (2012). Pengembangan Kreativitas Anak Berbakat. Jakarta: Rineka Cipta.

Putra, H. D., Akhdiyat, A. M., Setiany, E. P., \& Andiarani, M. (2018). Kemampuan Berpikir Kreatif Matematik Siswa SMP di Cimahi. Kreano, Jurnal Matematika Kreatif-Inovatif, 9(1), 47-53. https://doi.org/10.15294/kreano.v9i1.12473

Rhosalia, L. A. (2016). Kemampuan Berpikir Kreatif Dalam Menulis Naratif Siswa Kelas V Sekolah Dasar Negeri Di Kecamatan Gayungan Surabaya. Jurnal Review Pendidikan Dasar: Jurnal Kajian Pendidikan Dan Hasil Penelitian, 2(2), 166. https://doi.org/10.26740/jrpd.v2n2.p166-174

Rismiyenti, R. (2018). Penggunaan Media Gambar Untuk Meningkatkan Motivasi Belajar Mata Pelajaran Seni Budaya (Tari) Murid Kelas Vii.4 Smpn 21 Pekanbaru. Dinamisia: Jurnal $\begin{array}{llll}\text { Pengabdian Kepada } & \text { Masyarakat, }\end{array}$ https://doi.org/10.31849/dinamisia.v2i1.1093

Sari, Y. D., \& Swestin, G. (2015). Tingkat Pengetahuan Siswa Sd Bina Putra Surabaya Tentang Majalah Dinding Sekolah. Scriptura, 4(2), 78-85. https://doi.org/10.9744/scriptura.4.2.7886

Satria, D., \& Afnita. (n.d.). Peningkatan keterampilan menulis dan mengelola majalah dinding sdn 04 dan sdn 10 lawang mandahiling kabupaten tanah datar, 217-225.

Yunus, M. M. (2017). Keterampilan menulis dan permasalahannya, 03(9), 62-67. 